\title{
Evaluation of agreement among digital dermatitis scoring methods in the milking parlor, pen, and hoof trimming chute
}

\author{
G. Cramer, ${ }^{*} 1$ T. Winders, $†$ L. Solano, $\ddagger$ and D. H. Kleinschmit§ \\ *Department of Veterinary Population Medicine, University of Minnesota, St. Paul 55108 \\ †Department of Animal Science, University of Nebraska-Lincoln, Lincoln 68583 \\ ¥Farm Animal Care Associates, Calgary, Alberta, Canada T2L 0T6 \\ §Zinpro Corporation, 10400 Viking Dr., Eden Prairie, MN 55344
}

\begin{abstract}
Digital dermatitis (DD) is the most common infectious foot lesion affecting welfare and productivity of dairy cattle. The key to DD control programs is routine and frequent identification of DD lesions. The objective was to evaluate accuracy of detecting and scoring DD lesions in 3 milking parlor designs and in 3 alternative settings compared with scoring in the hoof trimming chute as reference. A total of 552 cows and 1,104 hind feet from 17 freestall farms were scored by 1 observer in the milking parlor and in 1 other setting: pen, headlocks, or management rail. After being scored in the milking parlor and at least 1 other setting, cows were examined in the hoof trimming chute, considered the gold standard. In every setting, all hind feet were inspected visually using a flashlight and without prior washing of feet. Agreement of the scoring settings was assessed using the $5 \mathrm{M}$-stage scoring system and a dichotomous absence (M0 or M0/M1) or presence (M1 to M4.1 or M2 to M4.1) system. At trimming chute inspection, $44 \%$ of feet had a DD lesion, with estimates of $11,5,2,10$, and $16 \%$ for M1, M2, M3, M4, and M4.1 lesions, respectively. Apparent DD foot-level prevalence at the milking parlor, pen, management rail, and headlocks was $28,22,16$, and $22 \%$, respectively. M-stages were less discernible in the pen, management rail, and headlocks (apparent prevalence of M1, M2, M3, and M4.1 was $\leq 1 \%$ ) compared with the trimming chute and milking parlor. Agreement beyond chance between any scoring setting and trimming chute scoring ranged from 0.48 to 0.70 for the dichotomous scoring system (absence $=\mathrm{M} 0 / \mathrm{M} 1$ vs. presence $=\mathrm{M} 2$ to M4.1). Diagnostic test performance varied greatly among DD scoring settings but, in general, it had low sensitivity $(<70 \%)$ and high specificity $(>93 \%)$ for detecting any DD lesion. Agreement and test characteristics were not
\end{abstract}

Received August 28, 2017.

Accepted November 5, 2017.

${ }^{1}$ Corresponding author: gcramer@umn.edu affected by the type of milking parlor. Although the milking parlor and headlocks were the most reliable settings in which to detect DD, none of the settings were reliable enough to replace inspection of feet in the trimming chute. However, scoring the presence or absence of DD in the milking parlor, pen, management rail, and headlocks could be used to estimate within-herd DD prevalence, to improve DD surveillance through routine monitoring, and to evaluate effects of interventions at the farm level.

Key words: digital dermatitis, pen walk, diagnostic test, dairy cattle, hoof trimming

\section{INTRODUCTION}

Digital dermatitis (DD) is one of the most common foot lesions in confined dairy cattle, affecting 70 to $94 \%$ of herds (Cramer et al., 2008; USDA, 2009; Solano et al., 2016) and approximately $20 \%$ of cows at the time of hoof trimming (Holzhauer et al., 2006; Cramer et al., 2008; Solano et al., 2016). The disease has considerable negative economic impact on milk production and reproductive performance (Relun et al., 2013; Gomez et al., 2015), causes increased treatment and labor costs (Bruijnis et al., 2010; Cha et al., 2010), and poses a serious welfare concern due to pain and discomfort (Bruijnis et al., 2012).

Digital dermatitis is polybacterial, with Treponema spp. consistently present in lesions and considered to have an important causative role (Evans et al., 2008; Gomez et al., 2012; Krull et al., 2014). Clinically, the disease is characterized by circumscribed ulcerative or hyperkeratotic lesions predominantly affecting the plantar aspect of the interdigital cleft or the interdigital space of the foot (Read and Walker, 1998; Berry, 2001). The course of DD infection progresses through distinct morphological stages. Several classification systems for DD have been developed based on clinical (Laven, 1999; Manske et al., 2002; Vink, 2006) and combined clinical and microbiological findings (Döpfer et al., 1997; Krull et al., 2014). Nevertheless, the M-stage scoring sys- 
tem, developed by Döpfer et al. (1997) and amended by Berry et al. (2012), is currently the most widely adopted scoring system (Greenough et al., 2008; Zinpro International Bovine Lameness Committee, 2014) and characterizes 5 clinical stages of DD based on clinical appearance.

To minimize the detrimental effects of DD on the animal and the farm, rapid detection methods are needed. In addition, an accurate rapid scoring method would facilitate evaluation of the effect of changes to management practices at the herd level; for example, monitoring DD before and after changing footbathing practices (Solano et al., 2017b). Locomotion scoring is commonly used to identify lame cows (Sprecher et al., 1997; Flower and Weary, 2006); however, it is not a sensitive diagnostic test for DD because a large proportion of cows with DD are not lame (Cramer, 2007).

The gold standard for diagnosing DD is visual inspection of the foot in a hoof trimming chute; however, this is not an efficient method of detection due to the labor, time, cost, and disruption in a cow's time budget. Consequently, alternative scoring areas and methods have been developed to identify cows with DD in the milking parlor (Thomsen et al., 2008; Relun et al., 2011; Stokes et al., 2012; Solano et al., 2017a), in headlocks, or during pen walks (Jacobs et al., 2017). Various methods have been used to score cows in the milking parlor, including with a mirror (Relun et al., 2011; Solano et al., 2017a) or borescope (Laven, 1999; Stokes et al., 2012), without any tool (Rodriguez-Lainz et al., 1998; Thomsen et al., 2008; Oliveira et al., 2017), or without prior washing of cows' feet (Oliveira et al., 2017). Both the milking parlor and pen walk studies compared DD scores to the gold standard of hoof trimming chute inspection. Methods used by Laven (1999) and Stokes et al. (2012) were considered impractical due to the cost of the tool used and the effect on milking duration. Most of these studies evaluated only a few farms and the accuracy of the detection method was affected by the difficulty in accessing hind feet in certain parlor configurations (Thomsen et al., 2008; Stokes et al., 2012). In addition to the effect of milking parlor design and tool used, the various DD scoring systems used among studies make it difficult to compare detection methods. In most studies, the more detailed the description of lesions attempted (e.g., by color, depth, or stage), the lower the agreement and test characteristics compared with the gold standard. Conversely, the highest agreement generally results from simplifying DD into "present" and "absent" (Relun et al., 2011; Stokes et al., 2012; Solano et al., 2017a). Currently, most alternative scoring method studies have attempted to score DD in the milking parlor. However, scoring DD in areas other than the milking parlor could be useful because different parlor designs likely affect accuracy of DD detection (Thomsen et al., 2008), and scoring in the milking parlor can be disruptive to the milking process. Furthermore, with the increasing presence of automatic milking systems worldwide, there is a need for alternative scoring areas.

The objective was to evaluate the accuracy of detecting and scoring DD lesions in 3 parlor designs and in 3 alternative settings compared with scoring in the hoof trimming chute as reference. Our hypothesis was that there is a difference in test characteristics among the 3 parlor types and alternative settings.

\section{MATERIALS AND METHODS}

\section{Farm and Cow Selection}

A total of 17 farms in Wisconsin $(\mathrm{n}=5)$ and Minnesota $(n=12)$, clients of hoof trimmers, veterinarians, nutritionists, and Zinpro Corporation's field staff, were recruited by e-mail and telephone to be enrolled in this convenience sample study. Eligible farms met the following criteria: freestall housing; a herringbone, parallel, or rotary milking parlor; a professional hoof trimmer employed regularly; and endemic DD. Farms were selected mainly on parlor type, with a goal of including 10, 5 , and 5 herringbone, parallel, and rotary parlors, respectively. Data were collected between May and August 2014. All procedures were approved by the University of Minnesota Institutional Animal Care and Use Committee (1312-31180A).

Selected farms were visited before or on the day of hoof trimming. Sampling of study cows was a purposive selection of cows for trimming determined by farm personnel as part of the farm's regular hoof trimming schedule.

\section{Feet Assessment}

On 16 of the farms, cows' hind feet were scored for DD in the milking parlor and in 1 additional setting: pen, headlocks, or management rail. On 1 farm, feet were scored in the milking parlor and in 2 additional settings. A single observer (second author) scored all cows in all settings, by approaching cows from behind and observing the hind feet while cattle were restrained (in headlocks, milking parlor, or management rail) or free roaming (in pen). While scoring cows at the headlocks, management rail, and pen, the observer tried to get as close as possible to the cows' hind feet by slightly bending or squatting. In all settings, hind feet were scored without prior cleaning or washing. Illumination levels and type (natural light, artificial light, or both) 
Table 1. Description of scoring system for digital dermatitis

\begin{tabular}{ll}
\hline M-stage $^{1}$ & Stage description \\
\hline M0 & Normal digital skin without clinical signs of dermatitis. \\
M1 & Early, small, circumscribed lesions, red-gray epithelial defect of $<2 \mathrm{~cm}$ in diameter that precedes the acute stage. \\
M2 & Acute, ulcerative (bright red) or granulomatous (red-gray) digital skin alteration of $\geq 2 \mathrm{~cm}$ in diameter. Can be painful. \\
M3 & Ulcerated lesion has covered itself with a dry brown, firm scab-like material; evidence of healing. Not painful. \\
M4 & Chronic stage with dyskeratotic (mostly thickened epithelium) or proliferative growth. \\
M4.1 & Chronic lesion that displays a small M1 stage. \\
\hline
\end{tabular}

${ }^{1}$ Developed by Döpfer et al. (1997) and amended by Berry et al. (2012).

varied among farms. Therefore, a flashlight (Coast PX 25 Coast Products Inc., Portland, OR) was used at all times to improve lighting while scoring.

Scoring DD while cows were restrained in headlocks occurred during the farms' regular lock-up times and was done by walking through the feed aisle and approaching cows' hind feet. Scoring DD while cows were roaming freely in the pen was done inside the pen as the observer calmly walked past the hind feet of each selected cow and has been described as "pen walks" by Tremblay et al. (2016) and Jacobs et al. (2017).

Scoring DD in the management rail setting occurred in the farm's herringbone palpation facility (also known as the palpation rail) or in the return lane. Management rails are described in Holmes et al. (2013) and are used to restrain multiple cows for management procedures. Briefly, they consist of front and rump pipes running parallel to each other and positioning cows in a herringbone style. Scoring DD in the management rail or return lane setting was done by walking behind the cows and approaching their hind legs as closely as possible. These facilities will be simply referred to here as "rail."

The distance between the observer and cows' hind feet ranged from $30 \mathrm{~cm}$ to $2 \mathrm{~m}$ depending on scoring setting and safety conditions, the shortest distance being for milking parlor scoring and the longest for pen scoring. The time spent evaluating each cow was not recorded but it varied depending on setting and cow restraint. It was estimated to take 10 to $90 \mathrm{~s}$ per cow, the shortest observations occurring at the milking parlor and the slowest during pen scoring. After being scored in the parlor and at least 1 additional setting, cows were examined in the hoof trimming chute within $24 \mathrm{~h}$. In all settings, only hind feet were inspected, based on reports that approximately $95 \%$ of DD lesions occur on the hind feet (Cramer et al., 2008; Solano et al., 2016).

\section{DD Lesion Assessment}

All DD lesions were recorded using the modified Mstage scoring system (Table 1) according to Berry et al. (2012), which includes an additional M4.1 stage com- pared with the original M-stage scoring system (Döpfer et al., 1997). All data were collected by 1 observer (second author), who was trained to identify and score DD lesions by a person experienced in scoring the disease. The training program consisted of several steps. First, the observer reviewed labeled and described pictures from a library of resources, and from a draft version of Zinpro's DD Check App (Tremblay et al., 2016). Second, the observer and trainer reviewed unlabeled pictures and together evaluated cows in the hoof trimming chute and in all scoring settings. During these sessions, the observer and trainer discussed discrepancies to arrive at a consistent score. Finally, the observer and trainer scored 800 cows on 1 farm in a rotary parlor and scored 2 pens of approximately 400 cows while they were restrained in headlocks. No formal quantitative evaluation of agreement was completed between observer and trainer.

At the trimming chute inspection, cows' hind feet were cleaned with paper towels, and a curved hemostat and flashlight were used to open and thoroughly inspect the interdigital space. This inspection occurred as the hoof trimmer was trimming other feet and was done before any treatment. Digital dermatitis lesion location was not recorded, as the outcome of interest was infection status rather than anatomic location. If more than one DD lesion on the same foot was detected during inspection at the trimming chute, they were considered part of the same lesion complex and only the most severe lesion was recorded. In this case, M2 was considered the most severe lesion, followed by M4.1, M4, M3, and M1. All data were recorded using paper forms at the time of scoring and then entered into a database program (Apache OpenOffice 4.1.0, Apache Software Foundation, Forest Hill, MD).

\section{Statistical Analyses}

Before study initiation, a sample size calculation was performed using the foot as the unit of interest. This analysis indicated that a minimum of 205 feet would be required to reach the desired sensitivity of $90 \%$ and specificity of $85 \%$, with an estimated true prevalence 
of $30 \%$ and desired precision of $7.5 \%$ in each scoring setting (Hajian-Tilaki, 2014). This served as the basis for creating the selection criteria of at least 5 farms per parlor type and a minimum of 25 cows selected for trimming on each farm. Additional herds were included in the herringbone milking parlor category because of the expected higher level of variation of foot visibility in this milking parlor design.

Data were exported from the database program and merged and analyzed in Stata 13.1 (Stata Corp., College Station, TX). For all analyses, $P<0.05$ was considered significant. The unit of analysis was the individual foot (Relun et al., 2011; Jacobs et al., 2017; Solano et al., 2017a). Chi-squared tests were used to compare the proportion of each M-stage between trimming chute inspection and each of the alternative scoring settings.

Cohen's kappa statistic ( $\boldsymbol{\kappa})$, sensitivity (Se), specificity $(\mathbf{S p})$, positive predictive value, and negative predictive value were calculated to evaluate the performance of each scoring setting. Each system was compared with DD status as determined during the trimming chute evaluation (considered the gold standard). Cohen's $\kappa$ measured the actual agreement beyond chance and was calculated as (observed agreement - expected agreement $) /(1$ - expected agreement $)$ and was interpreted according to the following guidelines: $\leq 0=$ poor, 0.01 to $0.20=$ slight, 0.21 to $0.40=$ fair, 0.41 to $0.60=$ moderate, 0.61 to $0.80=$ substantial, 0.81 to $1.0=$ almost perfect agreement (Dohoo et al., 2009).

Sensitivity was defined as the proportion of feet with a DD lesion in the trimming chute that were identified as having DD in each of the alternative scoring settings. Specificity was defined as the proportion of feet without DD in the trimming chute that were identified as not having DD in each of the alternative scoring settings. Positive predictive value was defined as the probability that a foot identified as having DD in an alternative scoring setting, actually is affected by DD. Negative predictive value was defined as the probability that a foot identified as not having a DD lesion in an alternative scoring setting was actually not affected by DD. True prevalence was calculated as (apparent prevalence $+\mathrm{Sp}-1) /(\mathrm{Se}+\mathrm{Sp}-1)($ Dohoo et al., 2009).

The $\kappa$ statistics were calculated using all 5 M-stages together. Additionally, $\kappa$, Se, and Sp were calculated by dichotomizing the $\mathrm{M}$ scoring system into either absent or present using various classifications (i.e., absent was classified as M0 or M0/M1). Confidence intervals for $\kappa$ were estimated using bias-corrected estimations of the bootstrap method, set to 1,000 replications (Reichenheim, 2004). Differences between parlor types were compared by evaluating confidence intervals of the Se and Sp estimates for each type of parlor. In addition, logistic regression models were used to evaluate the ef- fect of the type of milking parlor on Se and Sp, and included farm as a random effect (Dohoo et al., 2009). These models assessed associations between the outcome of interest, absence or presence of DD at cow level during milking parlor evaluations (absent classified as M0 or M0/M1), and type of milking parlor as the only explanatory variable.

\section{RESULTS}

A total of 552 cows $(n=1,126$ feet $)$ were evaluated in 17 farms with a median of 31 cows per herd (range: 25-76). Lactating herd size ranged from 100 to 4,200 cows. Farms used a variety of bedding surfaces including sand, wood shavings, straw, and manure solids. Foot bathing frequency ranged from daily to monthly with a median of 4 times per week. Twenty-two of the 1,126 observations $(\mathrm{n}=1,104)$ were excluded from these analyses, as they only had a parlor score and no corresponding score in the hoof trimming chute $(\mathrm{n}=$ 14) or they did not have a corresponding parlor score $(\mathrm{n}=8)$.

At trimming chute inspection, $57 \%$ of cows and $44 \%$ of feet had a DD lesion. True prevalence estimates of $\mathrm{DD}$ at the cow level were $14,9,2,11$, and $22 \%$ for M1, M2, M3, M4, and M4.1 lesions, respectively. In our nonrandom sample, mean within-herd DD prevalence was $58 \%$ and ranged from 26 to $75 \%$ of cows affected.

At the foot level, apparent DD prevalence in the milking parlor, pen, rail, and headlocks was 28, 22, 16, and $22 \%$, respectively. Distribution of the proportion of M-stages differed between trimming chute scoring and any other scoring setting and parlor type $(P<0.001$; Tables 2 and 3); and M-stages were less discernible in the pen, rail, and headlocks (apparent prevalence of M1, M2, M3, and M4.1 was $\leq 1 \%$ ) compared with the trimming chute and milking parlor.

The $\kappa$ estimates for each scoring setting and parlor type are shown in Table 4. Agreement between any scoring setting and trimming chute scoring was fair (ranged from 0.19 to 0.45 ) for the $5 \mathrm{M}$-stage scoring system. Dichotomization of the scoring system improved agreement to moderate or substantial. Diagnostic test performance varied greatly among DD scoring settings, but in general it had low Se $(<70 \%)$ and high Sp (>93\%) for detecting DD (Table 5). When the system was evaluated as a screening test for cows in need of treatment (i.e., cows with only M2 lesions), agreement was slight $(\kappa=0.15)$, Se was very low $(9.4 \%)$, and Sp was high $(99.7 \%)$. Sensitivity and Sp were not affected by the type of milking parlor, as indicated by the overlapping confidence intervals (Table 5), and further confirmed by logistic regression. In that regard, type of milking parlor was not associated with DD presence or 
Table 2. Proportion (no., \% in parentheses) of each digital dermatitis (DD) M-stage score attributed in the hoof-trimming chute, milking parlor, pen, management rail, and headlocks on 1,104 hind feet of dairy cattle

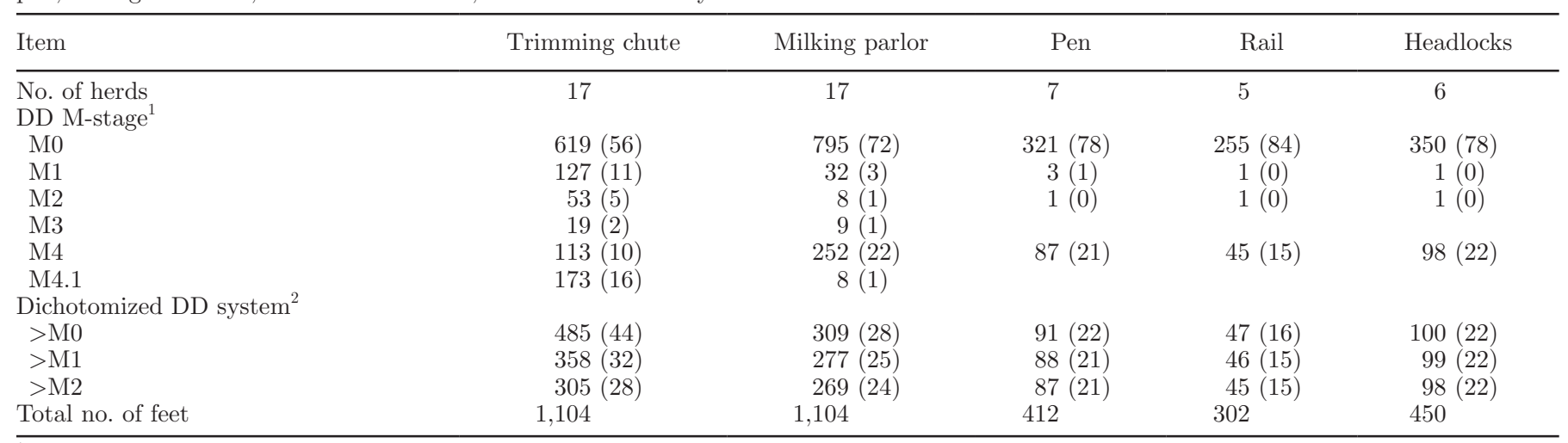

${ }^{1}$ Scored according to Berry et al. (2012).

${ }^{2} \mathrm{Where}>\mathrm{M} 0=\mathrm{M} 1 / \mathrm{M} 2 / \mathrm{M} 3 / \mathrm{M} 4 / \mathrm{M} 4.1 ;>\mathrm{M} 1=\mathrm{M} 2 / \mathrm{M} 3 / \mathrm{M} 4 / \mathrm{M} 4.1$; and $>\mathrm{M} 2=\mathrm{M} 3 / \mathrm{M} 4 / \mathrm{M} 4.1$.

absence $(P>0.25)$ and was therefore ignored in further analyses.

Predictive values changed remarkably as DD prevalence varied from 10 to $35 \%$ (Table 6). Estimates of true within-herd prevalence ranged from 1.4 to $92.7 \%$ depending on scoring setting and apparent prevalence (Table 7).

\section{DISCUSSION}

This study is apparently the first to evaluate accuracy of detecting and scoring DD in 4 alternative settings without any tool or prior washing of cows' feet, compared with scoring DD in the hoof trimming chute as reference. The milking parlor and headlocks were the

Table 3. Proportion (no., \% in parentheses) of each digital dermatitis (DD) M-stage score in 3 milking parlor types on 1,104 hind feet of dairy cattle

\begin{tabular}{lccc}
\hline & \multicolumn{3}{c}{ Milking parlor type } \\
\cline { 2 - 4 } Item & Parallel & Herringbone & Rotary \\
\hline No. of herds & 5 & 9 & 3 \\
DD M-stage & & & \\
M0 & $202(71)$ & $391(70)$ & $202(77)$ \\
M1 & $11(4)$ & $16(3)$ & $5(2)$ \\
M2 & $3(1)$ & $5(1)$ & \\
M3 & $4(1)$ & $5(1)$ & \\
M4 & $62(22)$ & $134(24)$ & $56(21)$ \\
M4.1 & $2(1)$ & $5(1)$ & $1(0)$ \\
Dichotomized DD system & \\
>M0 & $82(29)$ & $165(30)$ & $62(23)$ \\
>M1 & $71(25)$ & $149(27)$ & $57(22)$ \\
> M2 & $68(24)$ & $144(26)$ & $57(22)$ \\
Total no. of feet & 284 & 556 & 264 \\
\hline
\end{tabular}

${ }^{1}$ Scored according to Berry et al. (2012).

${ }^{2}$ Where $>\mathrm{M} 0=\mathrm{M} 1 / \mathrm{M} 2 / \mathrm{M} 3 / \mathrm{M} 4 / \mathrm{M} 4.1 ;>\mathrm{M} 1=\mathrm{M} 2 / \mathrm{M} 3 / \mathrm{M} 4 / \mathrm{M} 4.1$; and $>\mathrm{M} 2=\mathrm{M} 3 / \mathrm{M} 4 / \mathrm{M} 4.1$. scoring settings with the highest accuracy in detecting presence of DD lesions, although accuracy was generally moderate and varied depending on how the scoring system was simplified.

Selection of cows was determined by farm personnel; therefore, our sample prevalence is likely biased due to the purposive sampling method. The presence of DD (44\%) at the foot level identified during trimming chute inspections, although potentially biased, is comparable with that reported in other validation studies from France and Canada (45\% in Relun et al., 2011; 37\% in Jacobs et al., 2017), but higher than those found in Denmark (16-29\% in Thomsen et al., 2008; V. H. S. Oliveira, Aarhus University, Tjele, Denmark; personal communication). Higher prevalence estimates were reported by Stokes et al. (2012) and Solano et al. (2017a), at 54 and $57 \%$, respectively, but this could be a consequence of differing study design and other factors, as the former study included data from only 1 herd and the latter selected herds based on $\geq 10 \%$ DD prevalence. Regarding M-stage-specific estimates, the prevalence $(5 \%)$ of lesions in need of topical treatment (M2 lesions) in the current study was comparable to the $6 \%$ reported by Solano et al. (2017a), but approximately one-half of that reported by Relun et al. (2011). In our sample, apparent DD prevalence in the milking parlor, pen, rail, and headlocks was roughly $50 \%$ lower than true DD prevalence detected in the trimming chute. In addition, M-stages other than M4 were infrequently observed in the pen, rail, and headlocks. Several factors may have limited detection of DD in the alternative scoring settings, including the distance between the observer and cows' hind feet, which ranged from approximately $30 \mathrm{~cm}$ to $2 \mathrm{~m}$; movement of the cows while scoring (cows could be restrained in headlocks, milking parlor and rail, or free roaming in the 
Table 4. Agreement beyond chance ( $\kappa, 95 \%$ CI in parentheses) between digital dermatitis scores attributed in the headlocks, pen, management rail, and milking parlor compared with the hoof trimming chute as the gold standard $(\mathrm{n}=1,104$ hind feet)

\begin{tabular}{lccc}
\hline & \multicolumn{3}{c}{ Digital dermatitis M-stage $^{1}$} \\
\cline { 2 - 4 } Scoring setting & $>\mathrm{M} 0^{2}$ & $>\mathrm{M}^{3}$ & Overall $^{4}$ \\
\hline Headlocks & $0.52(0.43-0.59)$ & $0.61(0.54-0.70)$ & $0.29(0.24-0.35)$ \\
Rail & $0.35(0.25-0.45)$ & $0.48(0.37-0.59)$ & $0.19(0.14-0.26)$ \\
Pen & $0.36(0.29-0.43)$ & $0.57(0.49-0.65)$ & $0.19(0.15-0.24)$ \\
Milking parlor & & & \\
Parallel & $0.56(0.46-0.65)$ & $0.75(0.66-0.83)$ & $0.32(0.26-0.39)$ \\
Herringbone & $0.48(0.41-0.55)$ & $0.64(0.57-0.70)$ & $0.25(0.21-0.30)$ \\
Rotary & $0.71(0.61-0.80)$ & $0.79(0.69-0.87)$ & $0.45(0.37-0.53)$ \\
All types & $0.55(0.51-0.60)$ & $0.70(0.66-0.75)$ & $0.31(0.28-0.34)$ \\
\hline
\end{tabular}

${ }^{1}$ Scored according to Berry et al. (2012).

${ }^{2}>\mathrm{M} 0=\mathrm{M} 1 / \mathrm{M} 2 / \mathrm{M} 3 / \mathrm{M} 4 / \mathrm{M} 4.1$.

${ }^{3}>\mathrm{M} 1=\mathrm{M} 2 / \mathrm{M} 3 / \mathrm{M} 4 / \mathrm{M} 4.1$.

${ }^{4}$ All M-stages (M0 to M4.1).

pen); size of the lesion; lighting conditions in the pen; and manure contamination of cows' feet.

The fair agreement $(\kappa=0.19-0.31)$ between all scoring settings and trimming chute inspection for all 5 M-stages together was lower than the moderate to almost perfect agreement reported by Relun et al. (2011), Solano et al. (2017a), and Stokes et al. (2012) $(\kappa=$ $0.44,0.59$, and 0.99 , respectively). This was expected because, in our study, hind feet were inspected and scored without assistance of a mirror and flashlight and without prior washing of cows' feet. The lack of a tool and the dirty feet likely reduced the observer's ability to detect color, size, and presence of lesions. The only 2 studies with similar methodology (omitting the use of a tool and washing cows' feet) did not assess agreement but suggested low reliability of the scoring test (Jacobs et al., 2017; Oliveira et al., 2017). One study focused on DD prevalence in young stock using pen walks and reported a Se of $62 \%$ and $\mathrm{Sp}$ of $98 \%$ (Jacobs et al., 2017), whereas the other did not use a gold standard but reported $32 \%$ more DD cases detected in cows with washed feet compared with unwashed feet (Oliveira et al., 2017). The higher Se reported by Jacobs et al. (2017) compared with our findings (lowest Se was in the rail: $34 \%$; highest Se was in the milking parlor: $58 \%$ ) could be due to differences in foot and leg conformation between young stock and adult cattle. The commonly steeper foot and higher heel depth of young animals (Boelling and Pollott, 1998) enables a clearer view of the interdigital cleft.

Optimized agreement and test characteristics between observations in the trimming chute and alternate scoring settings occurred when the scoring system was limited to the dichotomous DD presence or absence. In

Table 5. Evaluation of digital dermatitis (DD) using the M-scoring system as diagnostic or screening test ${ }^{1}$ for different scoring settings and various parlor types, considering the hoof trimming chute score as the gold standard ( $\mathrm{n}=1,104$ hind feet)

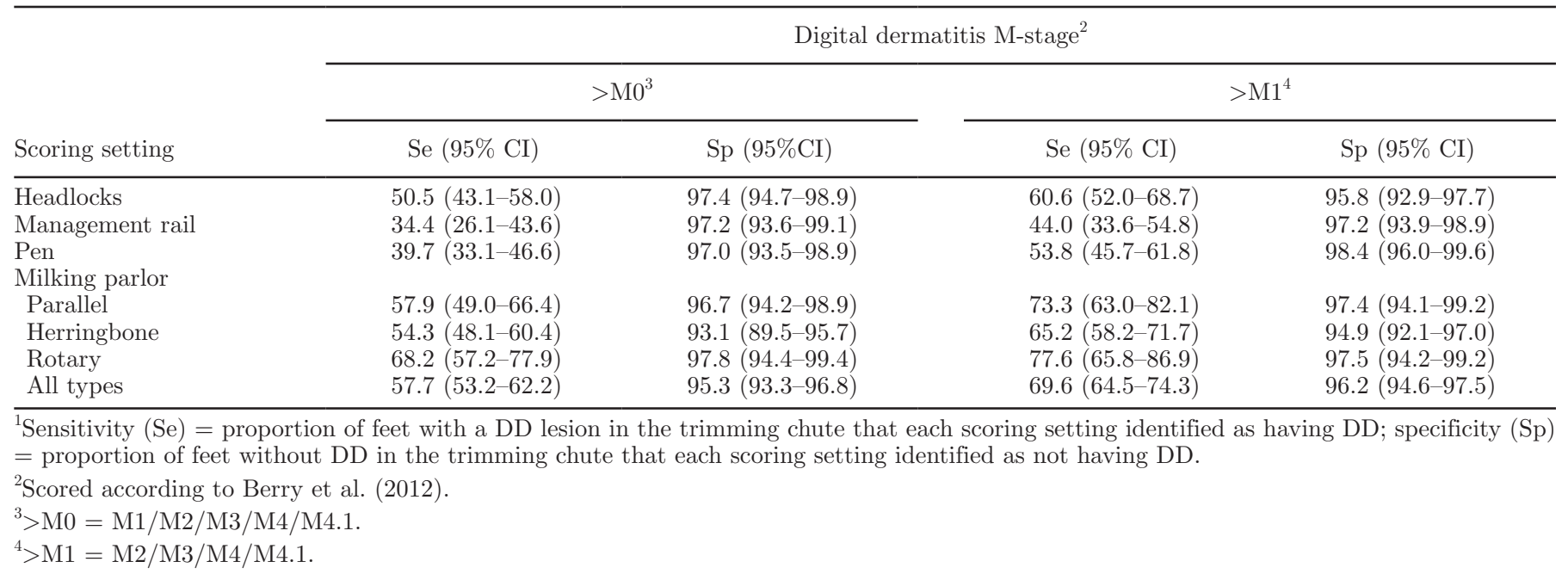


Table 6. Estimated positive (PPV) and negative (NPV) predictive values (95\% CI in parentheses) for the scoring of digital dermatitis ${ }^{1}$ [absence (M0/M1) vs. presence (M2/M3/M4/M4.1)] in different scoring settings and at various levels of true prevalence, using scoring in the hoof trimming chute as the gold standard $(\mathrm{n}=1,104$ hind feet)

\begin{tabular}{|c|c|c|c|c|c|c|c|c|}
\hline $\begin{array}{l}\text { True } \\
\text { prevalence (\%) }\end{array}$ & \multicolumn{2}{|c|}{ Milking parlor } & \multicolumn{2}{|c|}{ Headlocks } & \multicolumn{2}{|c|}{ Pen } & \multicolumn{2}{|c|}{ Management rail } \\
\hline 10 & $\begin{array}{l}67.3^{2} \\
(58.7-74.9)\end{array}$ & $\begin{array}{l}96.6 \\
(96.0-97.1)\end{array}$ & $\begin{array}{l}61.5 \\
(48.0-73.4)\end{array}$ & $\begin{array}{l}95.6 \\
(94.7-96.4)\end{array}$ & $\begin{array}{l}79.3 \\
(58.9-91.1)\end{array}$ & $\begin{array}{l}95.0 \\
(94.2-95.8)\end{array}$ & $\begin{array}{l}63.2 \\
(43.0-79.6)\end{array}$ & $\begin{array}{l}94.0 \\
(92.9-94.9)\end{array}$ \\
\hline 25 & $\begin{array}{l}86.1 \\
(81.0-89.9)\end{array}$ & $\begin{array}{l}90.5 \\
(89.0-91.7)\end{array}$ & $\begin{array}{l}82.7 \\
(73.4-89.2)\end{array}$ & $\begin{array}{l}87.9 \\
(85.6-89.9)\end{array}$ & $\begin{array}{l}92.0 \\
(81.1-96.8)\end{array}$ & $\begin{array}{l}86.5 \\
(84.4-88.4)\end{array}$ & $\begin{array}{l}83.7 \\
(69.4-92.1)\end{array}$ & $\begin{array}{l}83.9 \\
(81.2-86.2)\end{array}$ \\
\hline 35 & $\begin{array}{l}90.9 \\
(87.3-93.5)\end{array}$ & $\begin{array}{l}85.4 \\
(83.4-87.3)\end{array}$ & $\begin{array}{l}88.5 \\
(81.7-93.0)\end{array}$ & $\begin{array}{l}81.9 \\
(78.6-84.7)\end{array}$ & $\begin{array}{l}94.9 \\
(87.4-98.0)\end{array}$ & $\begin{array}{l}79.8 \\
(77.0-82.4)\end{array}$ & $\begin{array}{l}89.3 \\
(78.5-95)\end{array}$ & $\begin{array}{l}76.3 \\
(72.8-79.5)\end{array}$ \\
\hline
\end{tabular}

${ }^{1}$ Scored according to Berry et al. (2012).

${ }^{2}$ Interpretation example: At $10 \%$ true prevalence of digital dermatitis, when an M-stage is identified in the milking parlor, there is a $67 \%$ probability that the foot is truly affected.

our study, agreement improved from fair $(\kappa=0.19-0.31)$ to moderate or substantial $(\kappa=0.48-0.70)$ when using the simplified scoring system. A similar improvement was reported by Solano et al. (2017a) and Stokes et al. (2012). This improvement could be due to how DD lesion stages are categorized. The M1 stage is commonly misclassified as M0, because it can be easily missed due to its small size and common anatomical location, with $65 \%$ of M1 lesions occurring in the interdigital space (Relun et al., 2011; Solano et al., 2017a). Misclassification frequency and clinical relevance of M1 can justify merging M0 and M1 into a single category. Thus, in our study, dichotomizing M-stages into absence (M0 and M1) and presence (M2, M3, M4, and M4.1) most improved agreement and test characteristics. These results are consistent with several studies (Relun et al., 2011; Stokes et al., 2012; Jacobs et al., 2017; Solano et al., 2017a), providing evidence that, regardless of methodology and DD scoring system used, accuracy decreases when attempting to detect precise lesion characteristics or stages.

The accuracy of the scoring system at the $>$ M1 level was comparable to the sensitivity reported by studies where DD scoring was not assisted by using a tool (Rodriguez-Lainz et al., 1998; Thomsen et al., 2008), but inferior to studies that used either a mirror or a more in-depth, lengthier evaluation in the milking parlor (Relun et al., 2011; Stokes et al., 2012; Solano et al., 2017a). Scoring DD in the milking parlor had a higher Sp than reports from any other study. In addition, parlor type did not affect $\kappa$, Se, or Sp, which was contrary to inferred findings from Thomsen et al. (2008) and Relun et al. (2011). Given that our study scored more cows in each parlor type, our results indicate that the accuracy of DD detection was relatively consistent among parlor types.

Our findings for positive and negative predictive value suggested that scoring $\mathrm{DD}$ in the milking parlor could be a valuable screening test for cows in need of treatment in herds with a high DD prevalence $(\geq 25 \%)$. Because the scoring system, as implemented in this study, did not accurately differentiate between M2 and M4 stages, it would need to be used in conjunction with good hoof health records. To make this work, the DD status of each cow should be recorded at regular intervals and new cows identified with DD should be

Table 7. Estimated true prevalence of digital dermatitis (DD $)^{1}$ based on sensitivity and specificity for absence (M0/M1) and presence (M2/M3/M4/M4.1) of DD lesions, at various levels of apparent prevalence in different scoring settings

\begin{tabular}{lrcrc}
\hline & \multicolumn{4}{c}{ True prevalence (\%) } \\
\cline { 2 - 5 } $\begin{array}{l}\text { Apparent } \\
\text { prevalence (\%) }\end{array}$ & Parlor & Headlocks & Pen & Management rail \\
\hline 5 & 1.8 & 1.4 & 6.5 & 5.3 \\
10 & 9.4 & 10.3 & 16.1 & 17.5 \\
15 & 17.0 & 19.1 & 25.7 & 29.6 \\
20 & 24.6 & 28.0 & 35.2 & 51.7 \\
25 & 32.2 & 36.9 & 44.8 & 66.0 \\
30 & 39.8 & 45.7 & 54.4 & 78.2 \\
35 & 47.4 & 54.6 & 64.0 & 90.3 \\
40 & 55.0 & 63.5 & 73.6 & \\
45 & 62.6 & 72.3 & 83.1 & \\
50 & 70.2 & 81.2 & 92.7 & \\
\hline
\end{tabular}

${ }^{1}$ Scored according to Berry et al. (2012). 
brought to the trimming chute for evaluation and treatment.

If the goal of scoring DD is to establish a baseline prevalence of DD $>$ M1 before an intervention, results from Table 7 can assist in estimating true DD prevalence, based on the apparent DD prevalence on various scoring settings. Values in Table 7 were calculated using the study's results on Se and Sp for each scoring system. When using Table 7 in this manner, it is important to consider the external validity of our study. However, the Se $(<70 \%)$ and $\mathrm{Sp}(>93 \%)$ reported in this study were within the ranges described in the literature (Se: $62-100 \%$, Sp: 77-99\%; Rodriguez-Lainz et al., 1998; Vink, 2006; Stokes et al., 2012; Jacobs et al., 2017). Therefore, we conclude that our results are generalizable between populations of cows and scorers.

Other factors that potentially affected accuracy of scoring DD in alternative settings included the observer and anatomical location of DD lesions. Our study used only 1 trained observer who did not have prior experience scoring DD. As demonstrated by Relun et al. (2011) and Solano et al. (2017a), observer agreement and reliability improved with training and practice. The lack of experience of our observer potentially had a negative effect on results. However, it is likely that these results are more representative of observations that would be made by farmers, veterinarians, staff, or other industry stakeholders with little training. In addition, anatomic location of DD lesions was not recorded, but it was evident that lesions in the interdigital space went completely undetected by alternative scoring settings. Hence, although it was not possible to estimate precisely the extent to which lesion location affected test performance, based on previous studies, 5 to $10 \%$ of DD lesions occur in the interdigital space (Relun et al., 2011; Solano et al., 2017a).

Based upon the literature, the main factors that could improve performance of the scoring system are increased time for scoring (Rodriguez-Lainz et al., 1998; Laven, 1999; Stokes et al., 2012), scoring with the addition of more sophisticated equipment (Laven, 1999; Relun et al., 2011; Solano et al., 2017a), washing cows' feet before DD scoring (Jacobs et al., 2017; Oliveira et al., 2017), and experience of the observer in scoring DD lesions (Thomsen et al., 2008; Relun et al., 2011). Washing cows' feet would improve the ability to visualize lesions but, anecdotally, farmers are generally reluctant to do it as it promotes defecation. Besides disrupting the milking process, washing cows' feet manually is not a feasible practice in farms without a milking parlor (or with automatic milking systems) and when cows or young stock are on pasture, corrals, or dirt lots. In addition, the more complicated the scoring process, the less likely it is to be implemented by dairy producers or their advisors.

\section{CONCLUSIONS}

The milking parlor and headlocks were the most reliable settings for inspection of feet to detect DD lesions without the assistance of any tool or foot cleaning. The type of parlor did not influence the level of agreement $(\kappa)$, Se, or Sp compared with scoring feet in the hoof trimming chute. The performance of the scoring system to differentiate various stages of DD was limited in all scoring settings compared with the trimming chute scoring. The use of a simplified scoring system based on absence or presence of DD would allow the dairy industry to screen cows for DD, facilitate prompt treatment, and evaluate effects of interventions at the farm level.

\section{ACKNOWLEDGMENTS}

This study was completed with funding from an unrestricted donation from Zinpro Corp. (Eden Prairie, MN). The authors thank participating farms, hoof trimmers, and industry supporters who helped recruit farms.

\section{REFERENCES}

Berry, S. L. 2001. Diseases of the digital soft tissues. Vet. Clin. North Am. Food Anim. Pract. 17:129-142. (vii.).

Berry, S. L., D. H. Read, T. R. Famula, A. Mongini, and D. Döpfer. 2012. Long-term observations on the dynamics of bovine digital dermatitis lesions on a California dairy after topical treatment with lincomycin $\mathrm{HCl}$. Vet. J. 193:654-658. https://doi.org/10 $.1016 /$ j.tvjl.2012.06.048.

Boelling, D., and G. E. Pollott. 1998. Locomotion, lameness, hoof and leg traits in cattle II. Livest. Sci. 54:205-215. https://doi.org/10 .1016/S0301-6226(97)00173-5.

Bruijnis, M. R. N., B. Beerda, H. Hogeveen, and E. N. Stassen. 2012. Assessing the welfare impact of foot disorders in dairy cattle by a modeling approach. Animal 6:962-970. https://doi.org/10.1017/ S1751731111002606.

Bruijnis, M. R. N., H. Hogeveen, and E. N. Stassen. 2010. Assessing economic consequences of foot disorders in dairy cattle using a dynamic stochastic simulation model. J. Dairy Sci. 93:2419-2432. https://doi.org/10.3168/jds.2009-2721.

Cha, E., J. A. Hertl, D. Bar, and Y. T. Grohn. 2010. The cost of different types of lameness in dairy cows calculated by dynamic programming. Prev. Vet. Med. 97:1-8. https://doi.org/10.1016/j .prevetmed.2010.07.011.

Cramer, G. 2007. Quantification of foot lesions and an evaluation of early detection methods for lameness in Ontario dairy farms. PhD thesis. University of Guelph, Guelph, ON, Canada.

Cramer, G., K. D. Lissemore, C. L. Guard, K. E. Leslie, and D. F. Kelton. 2008. Herd- and cow-level prevalence of foot lesions in Ontario dairy cattle. J. Dairy Sci. 91:3888-3895. https://doi.org/ $10.3168 /$ jds.2008-1135.

Dohoo, I., W. Martin, and H. Stryhn. 2009. Veterinary Epidemiologic Research. 2nd ed. VER Inc., Charlottetown, Prince Edward Island, Canada.

Döpfer, D., A. A. H. M. ter Huurne, J. L. Cornelisse, A. J. A. M. van Asten, A. Koopmans, F. A. Meijer, Y. H. Schukken, I. Szakáll, 
W. Klee, and R. B. Bosma. 1997. Histological and bacteriological evaluation of digital dermatitis in cattle, with special reference to spirochaetes and Campylobacter faecalis. Vet. Rec. 140:620-623. https://doi.org/10.1136/vr.140.24.620.

Evans, N. J., J. M. Brown, I. Demirkan, R. D. Murray, W. D. Vink, R. W. Blowey, C. A. Hart, and S. D. Carter. 2008. Three unique groups of spirochetes isolated from digital dermatitis lesions in UK cattle. Vet. Microbiol. 130:141-150. https://doi.org/10.1016/ j.vetmic.2007.12.019.

Flower, F. C., and D. M. Weary. 2006. Effect of hoof pathologies on subjective assessments of dairy cow gait. J. Dairy Sci. 89:139-146. https://doi.org/10.3168/jds.S0022-0302(06)72077-X.

Gomez, A., N. B. Cook, N. D. Bernardoni, J. Rieman, A. F. Dusick, R. Hartshorn, M. T. Socha, D. H. Read, and D. Döpfer. 2012. An experimental infection model to induce digital dermatitis infection in cattle. J. Dairy Sci. 95:1821-1830. https://doi.org/10.3168/jds $.2011-4754$.

Gomez, A., N. B. Cook, M. T. Socha, and D. Dopfer. 2015. Firstlactation performance in cows affected by digital dermatitis during the rearing period. J. Dairy Sci. 98:4487-4498. https://doi.org/10 $.3168 /$ jds.2014-9041.

Greenough, P. R., C. K. W. Muelling, D. Döpfer, and D. J. Tomlinson 2008. International atlas of lesions of cattle feet. Nomenclature and atlas update. Page 40 in Proc. 15th Int. Symp. 7th Conf. Lameness Ruminants, Kuopio, Finland. Savonia University of Applied Sciences, Kuopio, Finland.

Hajian-Tilaki, K. 2014. Sample size estimation in diagnostic test studies of biomedical informatics. J. Biomed. Inform. 48:193-204. https://doi.org/10.1016/j.jbi.2014.02.013.

Holmes, B., N. B. Cook, T. Funk, R. Graves, D. Kammel, D. Reinemann, and J. M. Zulovich. 2013. Dairy freestall housing and equipment. 8th ed. MidWest Plan Service, Ames, Iowa.

Holzhauer, M., C. Hardenberg, C. J. M. Bartels, and K. Frankena. 2006. Herd- and cow-level prevalence of digital dermatitis in the Netherlands and associated risk factors. J. Dairy Sci. 89:580-588. https://doi.org/10.3168/jds.S0022-0302(06)72121-X.

Jacobs, C., K. Orsel, and H. W. Barkema. 2017. Prevalence of digital dermatitis in young stock in Alberta, Canada, using pen walks. J. Dairy Sci. 100:9234-9244. https://doi.org/10.3168/jds.2017-13044.

Krull, A. C., J. K. Shearer, P. J. Gorden, V. L. Cooper, G. J. Phillips, and P. J. Plummer. 2014. Deep sequencing analysis reveals temporal microbiota changes associated with development of bovine digital dermatitis. Infect. Immun. 82:3359-3373. https://doi.org/ 10.1128/Iai.02077-14.

Laven, R. A. 1999. The environment and digital dermatitis. Cattle Pract. 7:349-354.

Manske, T., J. Hultgren, and C. Bergsten. 2002. Topical treatment of digital dermatitis associated with severe heel-horn erosion in a Swedish dairy herd. Prev. Vet. Med. 53:215-231.

Oliveira, V. H. S., J. T. Sørensen, and P. T. Thomsen. 2017. Can digital dermatitis be detected in the milking parlor without washing cows' feet? Res. Vet. Sci. 115:325-326. https://doi.org/10.1016/j .rvsc.2017.06.017.

Read, D. H., and R. L. Walker. 1998. Papillomatous digital dermatitis (footwarts) in California dairy cattle: Clinical and gross pathologic findings. J. Vet. Diagn. Invest. 10:67-76.
Reichenheim, M. E. 2004. Confidence intervals for the kappa statistic. Stata J. 4:421-428.

Relun, A., R. Guatteo, P. Roussel, and N. Bareille. 2011. A simple method to score digital dermatitis in dairy cows in the milking parlor. J. Dairy Sci. 94:5424-5434. https://doi.org/10.3168/jds $.2010-4054$.

Relun, A., A. Lehebel, A. Chesnin, R. Guatteo, and N. Bareille. 2013. Association between digital dermatitis lesions and test-day milk yield of Holstein cows from 41 French dairy farms. J. Dairy Sci. 96:2190-2200. https://doi.org/10.3168/jds.2012-5934.

Rodriguez-Lainz, A., P. Melendez-Retamal, D. W. Hird, and D. H. Read. 1998. Papillomatous digital dermatitis in Chilean dairies and evaluation of a screening method. Prev. Vet. Med. 37:197-207. https://doi.org/10.1016/S0167-5877(98)00091-9.

Solano, L., H. W. Barkema, C. Jacobs, and K. Orsel. 2017a. Validation of the M-stage scoring system for digital dermatitis on dairy cows in the milking parlor. J. Dairy Sci. 100:1592-1603. https:// doi.org/10.3168/jds.2016-11365.

Solano, L., H. W. Barkema, S. Mason, E. A. Pajor, S. J. LeBlanc, and K. Orsel. 2016. Prevalence and distribution of foot lesions in dairy cattle in Alberta, Canada. J. Dairy Sci. 99:6828-6841. https://doi .org/10.3168/jds.2016-10941.

Solano, L., H. W. Barkema, C. Pickel, and K. Orsel. 2017b. Effectiveness of a standardized footbath protocol for prevention of digital dermatitis. J. Dairy Sci. 100:1295-1307. https://doi.org/10.3168/ jds.2016-11464.

Sprecher, D. J., D. E. Hostetler, and J. B. Kaneene. 1997. A lameness scoring system that uses posture and gait to predict dairy cattle reproductive performance. Theriogenology 47:1179-1187.

Stokes, J. E., K. A. Leach, D. C. J. Main, and H. R. Whay. 2012. The reliability of detecting digital dermatitis in the milking parlour. Vet. J. 193:679-684. https://doi.org/10.1016/j.tvjl.2012.06.053.

Thomsen, P. T., I. C. Klaas, and K. Bach. 2008. Scoring of digital dermatitis during milking as an alternative to scoring in a hoof trimming chute. J. Dairy Sci. 91:4679-4682. https://doi.org/10 $.3168 /$ jds.2008-1342.

Tremblay, M., T. Bennett, and D. Döpfer. 2016. The DD Check App for prevention and control of digital dermatitis in dairy herds. Prev. Vet. Med. 132:1-13. https://doi.org/10.1016/j.prevetmed 2016.07.016.

USDA. 2009. Dairy 2007, Part IV: Reference of dairy cattle health and management practices in the United States. USDA:APHIS VS, CEAH. Fort Collins, CO. \#N494.0209. Accessed Nov. 18, 2017. https://www.aphis.usda.gov/animal_health/nahms/dairy/ downloads/dairy07/Dairy07_dr_PartIV.pdf.

Vink, W. D. 2006. Investigating the epidemiology of bovine digital dermatitis: Causality, transmission and infection dynamics. PhD Thesis. University of Liverpool, UK.

Zinpro International Bovine Lameness Committee. 2014. Cattle lameness: Identification, prevention and control of claw lesions. 1st ed. Zinpro Corp., Eden Prairie, MN 